\title{
Deposition and biokinetics of inhaled nanoparticles
}

Marianne Geiser ${ }^{1 *}$, Wolfgang G Kreyling ${ }^{2,3}$

\begin{abstract}
Particle biokinetics is important in hazard identification and characterization of inhaled particles. Such studies intend to convert external to internal exposure or biologically effective dose, and may help to set limits in that way. Here we focus on the biokinetics of inhaled nanometer sized particles in comparison to micrometer sized ones.

The presented approach ranges from inhaled particle deposition probability and retention in the respiratory tract to biokinetics and clearance of particles out of the respiratory tract. Particle transport into the blood circulation (translocation), towards secondary target organs and tissues (accumulation), and out of the body (clearance) is considered. The macroscopically assessed amount of particles in the respiratory tract and secondary target organs provides dose estimates for toxicological studies on the level of the whole organism. Complementary, microscopic analyses at the individual particle level provide detailed information about which cells and subcellular components are the target of inhaled particles. These studies contribute to shed light on mechanisms and modes of action eventually leading to adverse health effects by inhaled nanoparticles.

We review current methods for macroscopic and microscopic analyses of particle deposition, retention and clearance. Existing macroscopic knowledge on particle biokinetics and microscopic views on particle organ interactions are discussed comparing nanometer and micrometer sized particles. We emphasize the importance for quantitative analyses and the use of particle doses derived from real world exposures.
\end{abstract}

\section{Introduction}

It is expected that the use of nanomaterials and primarily of nanoparticulate materials will hold a key position in future science, technology and medicine. It spans from automotive, aircraft and space industry, to (bio) chemical and environmental engineering, to optics, electronics and communication technologies, to pharmacology and medicine, but also to day to day consumer products, i.e. to food, cosmetics and healthcare. The introduction of nanoparticulate materials is based on their exquisite properties and furthered by mandates of energy and resource savings. In this paper we will not focus on the manifold beneficial qualities of these new technologies but examine aspects of concern to pose risks for consumers and our societies. The exponentially increasing production of engineered nanoparticles urgently requires risk assessment of their potential for adverse health effects. Thereby, data for inhaled

\footnotetext{
* Correspondence: geiser@ana.unibe.ch

${ }^{1}$ Institute of Anatomy, University of Bern, Baltzerstrasse 2, CH-3000 Bern 9, Switzerland
}

nanoparticles is particularly important because (i) this is the major route for unwanted exposure, and (ii) there is ample and consistent evidence for adverse health effects being associated with increased concentrations of ambient fine and ultrafine particles (e.g. [1-5]). Also, for nanoparticles with anticipated beneficial use, e.g. as diagnostic tools or therapeutics in medicine [6,7] health risk assessment is necessary. Even already tested materials have to be included since nanoparticles tend to have different properties compared to larger particles of the same material [8]. Risk assessment comprises exposure assessment, hazard identification and characterization, as well as risk characterization. The Scientific Committee on Emerging and Newly Identified Health Risks (SCENIHR) of the European Commission emphasized in its recent report on Risk Assessment of Products of Nanotechnologies [9] a number of critical factors for assessing the impact of nanoparticles and health: (i) so far, exposure assessment for existing nanomaterials is rudimentary. (ii) hazardous nanomaterials need to be characterized both "as manufactured" and in the various 
possible forms "as delivered" in bio- and eco-systems, (iii) the current lack of a generally applicable paradigm for nanomaterial hazard identification demands a case by case approach for the risk assessment of nanomaterials.

Studies in humans or large animal species are limited; hence we have to resort to rodents to obtain sufficiently detailed data for risk assessment by inhaled particles [10].

The focus of this paper is hazard identification and characterization, which starts with dosimetry, i.e. the evaluation of the deposition pattern of inhaled particles and their subsequent dissemination (biokinetics) in the respiratory tract and the entire organism. Therein microscopic analyses at the individual particle level provide detailed information about which cells and subcellular components are targeted by inhaled particles. Such studies intend to convert external exposure to internal exposure or biologically effective dose, and may help to set limits in that way.

We present and discuss primarily the results from studies we performed on the deposition, retention and clearance, as well as on secondary organ translocation of (insoluble) nanoparticles at a macroscopic and a microscopic level in view of contributing to nanoparticle characterization and identification of their potential risk. We compare data from inhaled nanoparticles (particles $\leq$ $100 \mathrm{~nm}$ in diameter) with those from micrometer-sized particles with diameters from $100 \mathrm{~nm}$ up to $10 \mu \mathrm{m}$.
However, due to the blurred upper size limit of nanoparticles we consider micrometer-sized particles as those in the range of $0.5-10 \mu \mathrm{m}$. In addition, we include detailed methodological information allowing the application of protocols by the interested reader.

\section{Methods \\ Methods for macroscopic studies \\ Quantitative biokinetics}

Quantitative biokinetics can be performed after nanoparticle administration by any route: by inhalation or intratracheal instillation to the respiratory tract, by gavage to the gastro-intestinal tract, by intravenous or intra-arterial injection to the blood circulation and by dermal applications to the skin. The concept is simple, aiming to estimate the total amount of nanoparticles in the entire body at a certain time point after exposure and in all excretions until this time point. Hence, not only the distribution of nanoparticles in organs and tissues of interest is assessed, but nanoparticles in the remaining carcass and those excreted are also included. With this, a $100 \%$ balance to the administered nanoparticles is achieved and a complete, yet detailed, quantitative analysis of their biokinetics is obtained [11,12]. For this purpose, particle distribution is measured at several time points after particle exposure, as shown in Figure 1. Although this approach is applicable to any animal species, ethical, economic and practical reasons restrict quantitative biokinetics to small laboratory animals.

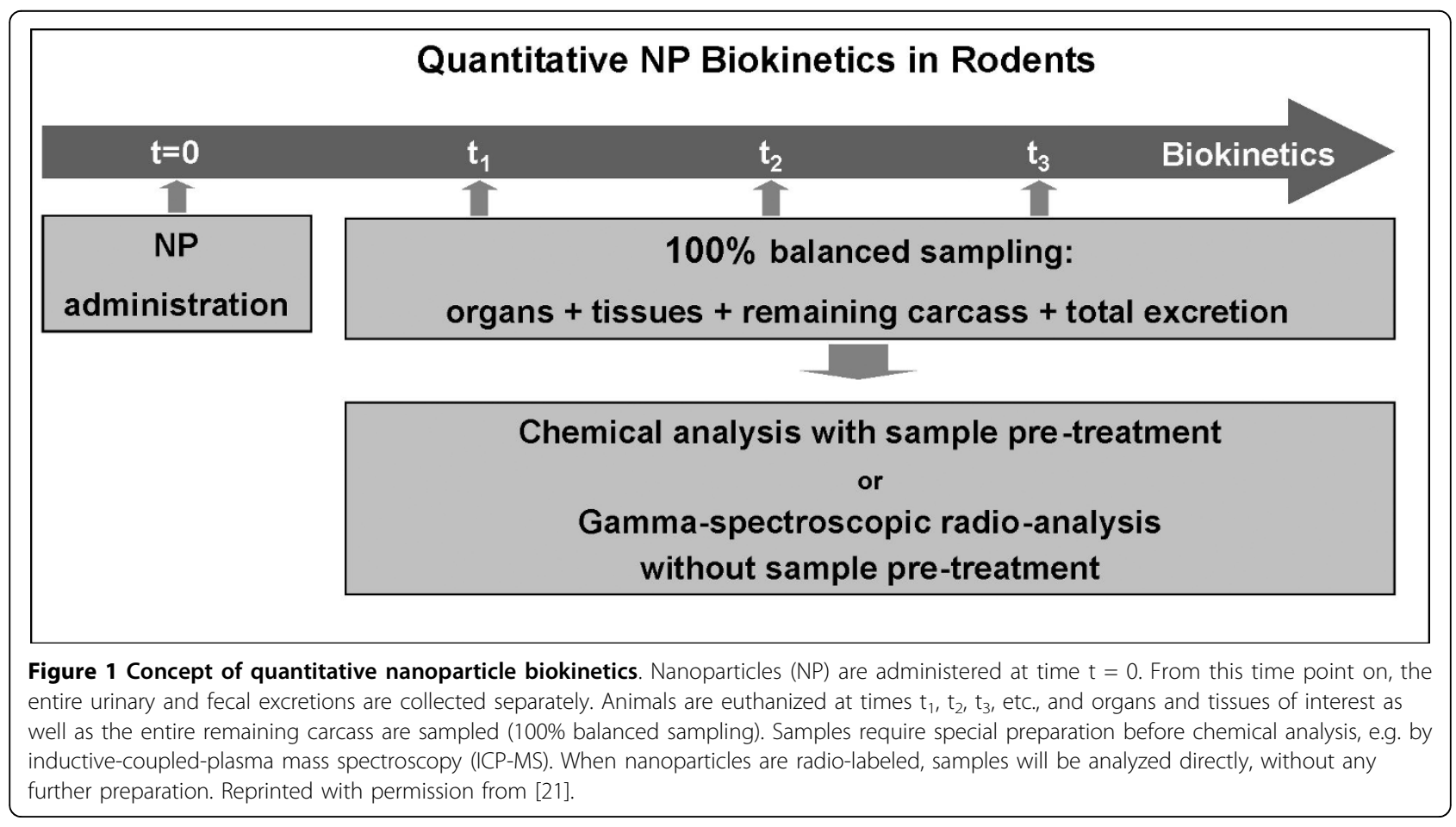


Analytical chemistry e.g. inductively coupled plasma mass spectroscopy (ICP-MS) or atomic absorption mass spectroscopy (AA-MS) provides suitable methods to quantify particles in the collected specimens. Thereby, special attention has to be paid to sample preparation, i. e. when nanoparticles need to be dissolved, the extremely low content of ions resulting from the very low nanoparticle mass may lead to substantial ion loss to the walls of the reaction vessels prior to sample analysis. Radio-spectroscopy may provide an elegant alternative, allowing direct analysis of native organs and tissues without any pre-treatment. In this case, the radio-label needs to be firmly integrated into the nanoparticle matrix without any leaching. While this requirement is hard to fulfill, when a radio-isotope is blended into the nanoparticles during production, stable labeling is obtained, when the radio-isotope belongs to the same chemical element as the nanoparticle matrix. The latter, requiring integration of the radio-label during nanoparticle production, however, is often difficult, since nanotechnology laboratories are usually not equipped with radio-chemistry instrumentation and the necessary permission. Nuclear reaction within the beforehand generated unlabeled nanoparticles upon neutron, proton or any other ion bombardment, allows radio-activation of one to a few atoms of the nanoparticles. Mostly, the amount of radioactivity is sufficiently high for subsequent radio-analysis, when a single atom per nanoparticle was converted by the nuclear reaction. A well known example is gold that is neutron-activated in a nuclear research reactor such that the gold nanoparticles are labeled with the ${ }^{198} \mathrm{Au}$ radio-isotope.

\section{Animals and organ preparation}

For our studies with radio-labeled nanoparticles [12,13], the deeply anesthetized (isoflurane 5\%) rats were killed by exsanguinations via the prepared abdominal aorta. Like this, about $70 \%$ of the total blood volume, estimated from the body weight, was collected. All organs and tissues, the remaining carcass as well as the total excretions were thereafter sampled for radio-analysis:

- Organs: lungs, liver, spleen, kidneys, reproductive organs, brain, heart, gastro-intestinal tract, blood, skin

- Tissues: samples of muscle and of bone (femur)

- Remainder: carcass beyond the listed tissues and organs

- Excretions: urine and feces, collected separately

To avoid any cross contamination, the organs were collected in toto and all body fluids were immediately removed, when vessels or excretory ducts had to be cut. Organs and tissue samples as well as the entire excretion were collected such that the entire organism was sampled and weighed in wet state.

The application of clean dissection techniques is essential to avoid cross contamination, in particular in inhalation studies, where fur contamination occurs upon whole body or nose-only exposures. Systematic changes of dissection tools and equipment are highly recommended. In addition, whole body vascular perfusion to empty the blood vessels within the organs is recommended to estimate particle retention in the parenchyma.

\section{Methods for microscopic studies}

Analysis of nanoparticles at the individual particle level by electron microscopy requires (i) adequate organ preservation, (ii) representative tissue sampling, and (iii) unambiguous identification of the nanoparticles in ultrathin tissue sections.

\section{Lung fixation}

The methods for tissue preservation using chemical fixative solutions are well established. The following methods are generally used for whole lung fixation:

Airway instillation

The fixative is introduced into the airways of a collapsed lung, in deeply anaesthetized animals or in cadaver lungs [14]. Thereby, the air spaces evenly expand and the interalveolar septa remain unfolded. Note: Airway instillation of (aqueous) fixatives does not preserve the lung lining layer and luminal cells, i.e. macrophages are dislocated from their native positions [15].

Vascular perfusion

Fixatives are delivered to the lungs via the blood vessels, while the airways and alveoli remain in their natural airfilled state $[14,16]$. This method is less effective in larger airways and especially of large animals, due to larger distance between vasculature and airway surface. Note: Fixation solely with glutaraldehyde, paraformaldehyde, or mixtures thereof, does not adequately preserve the lung lining layer and its associated luminal cells. Osmium tetroxide and uranyl acetate are necessary for cross-linking and stabilizing this layer $[17,18]$.

Other methods

Vapor fixation of lungs at a given pressure is a fast and technically easy method to preserve whole lungs (e.g. $[19,20])$. However, shrinkage and organ distortion occur and ultrastructural preservation of cells is inferior. Nonpolar fixatives, i.e. $1 \%$ osmium tetroxide dissolved in inert fluorocarbon (FC, Fluorinert ${ }^{\mathrm{m}}$ Liquid, $3 \mathrm{M}$, Belgium) are suitable to preserve large airways, either by immersion of excised specimens (Figure 2, [21]) or by airway instillation $[17,22,23]$. A variety of other fixation techniques have been developed in view to preserve the inner surface of airways and alveoli, but most of them cannot be used to fix whole lungs or even lung lobes (for review, see e.g. [17]).

\section{Recovery of phagocytic cells by bronchoalveolar lavage}

Particle uptake by airway and alveolar macrophages can be studied in two ways: (i) by fixing whole lungs or parts thereof to study the cells in situ, within their 

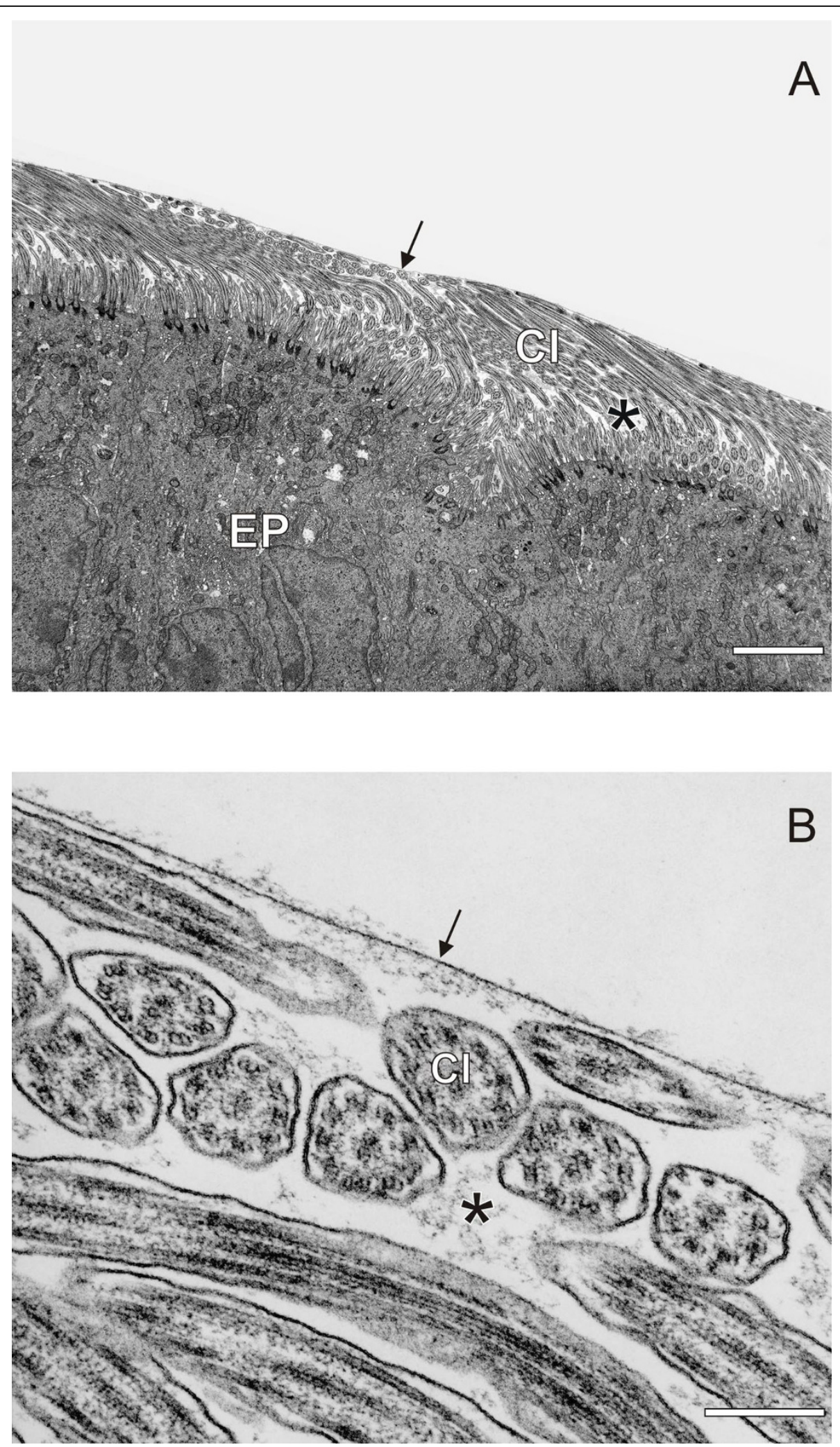

Figure 2 Micrographs of horse trachea fixed by immersion in non-polar fixative (A, B). Note that the lung lining layer (aqueous phase [asterix] and surfactant film at the air liquid interface [arrow]), has been preserved with this fixation technique. EP = epithelium, $\mathrm{Cl}=\mathrm{cilia}$. Bars: $(\mathrm{A})=2 \mu \mathrm{m},(\mathrm{B})=0.2 \mu \mathrm{m}$. Reprinted with permission from [21]. 
functional environment [24-26]; the cells' location on surfaces requiring special fixation protocols (see above); (ii) by isolating the cells from the organ and further processing for microscopic analysis; the lung surface cells being readily accessible to bronchoalveolar lavage (BAL).

In small laboratory animals, surface cells are usually recovered by whole lung lavage. In humans, BAL cells are recovered from the lower respiratory tract (bronchi, bronchioli and alveoli) using flexible fiberoptic bronchoscopy. The standard site of sampling is generally the middle lobe or lingula. Note: Not all macrophages will be recovered by BAL, and it is not known, whether these macrophages form a distinct population [27].

\section{Morphological characterization and elemental microanalysis of nanoparticles}

Unambiguous identification of nanoparticles in ultrathin tissue sections is a prerequisite and requires in most cases their morphologic classification as well as elemental microanalysis. Particle morphology is established (i) on aerosol samples collected directly on formvar coated tsansmission electron microscopy (TEM) grids using electrostatic precipitation and (ii) on ultrathin sections of aerosol samples collected on filters (Figure 3). Like this, the morphology of nanoparticles in $3 \mathrm{~d}$ as well as in $2 \mathrm{~d}$ (transects) is established.

Because there are other structures in the ultrathin tissue section that resemble the particles morphologically ("false positives"), additional elemental microanalysis of the nanoparticles by energy filtering transmission electron microscopy (EFTEM) (e.g. LEO 912, Zeiss, Oberkochen, Germany) is necessary. We have adapted three high resolution and sensitivity methods for elemental analysis of $\mathrm{TiO}_{2}$ nanoparticles in ultrathin sections [28], from which we routinely use electron spectroscopic imaging (ESI), where images are taken at a defined energy loss. Elemental (titanium) mapping is achieved with the three window method (Figure 4).

\section{Systematic uniform random tissue sampling and particle quantification}

To investigate the spatial and temporal distribution of particles in cells, tissues and organs quantitatively, specimen selection must confine to some randomness, i.e. ensure that every part of the organ and every orientation of a structure or particle therein have the same chance of being selected [29]. Systematic uniform random sampling, where the first item is selected at random position and orientation and the following ones in a predetermined interval, is most efficient and is superior to random sampling. Specimens for microscopic analysis are usually sampled in a hierarchical mode, called multistage or cascade sampling [30]. We have developed the 4-stage sampling protocol shown in Figure 5 for electron microscopic analysis of nanoparticles in lungs [26,31]. The last sample consists of fields, delimited by the bars of the hexagonal TEM grids, sampled on ultrathin sections of tissue or cell pellets. These hexagonal fields are then analyzed for the presence of particles with matching morphology and material properties. In case of inhaled $20 \mathrm{~nm} \mathrm{TiO}$, the particles have to correspond to transects of the aerosol particles and to consist of titanium upon elemental microanalysis $[26,31,28]$. Next, the nanoparticles are assigned to the compartments of interest.

Recent methods for quantifying nanoparticles using TEM sections have been reviewed in detail by Mayhew

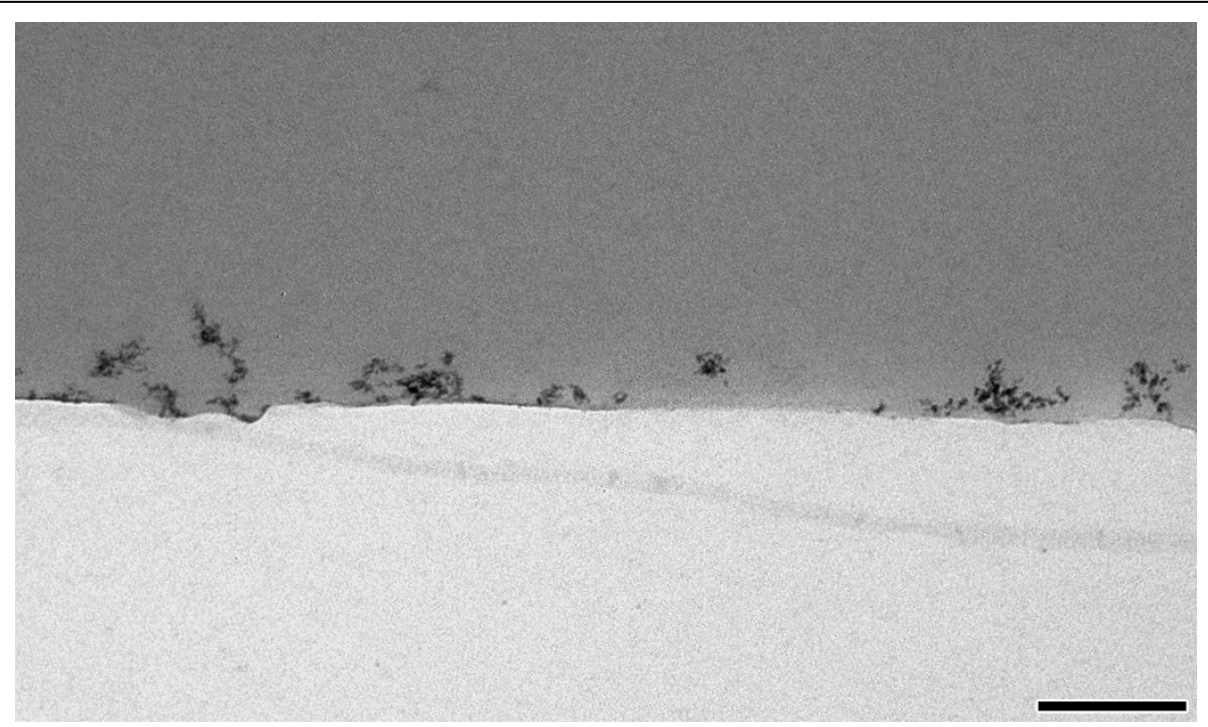

Figure 3 Nanoparticle morphology. Section profiles (transects) of $\mathrm{TiO}_{2}$ nanoparticles collected from the aerosol on filters, embedded in Epon and cut perpendicularly to the filter. Note that the as $20 \mathrm{~nm}$ measured $\mathrm{TiO}_{2}$ aerosol particles are already agglomerates of smaller primary particle structures of $3-5 \mathrm{~nm}$ formed immediately after spark ignition and condensation. Bar: $200 \mathrm{~nm}$. 

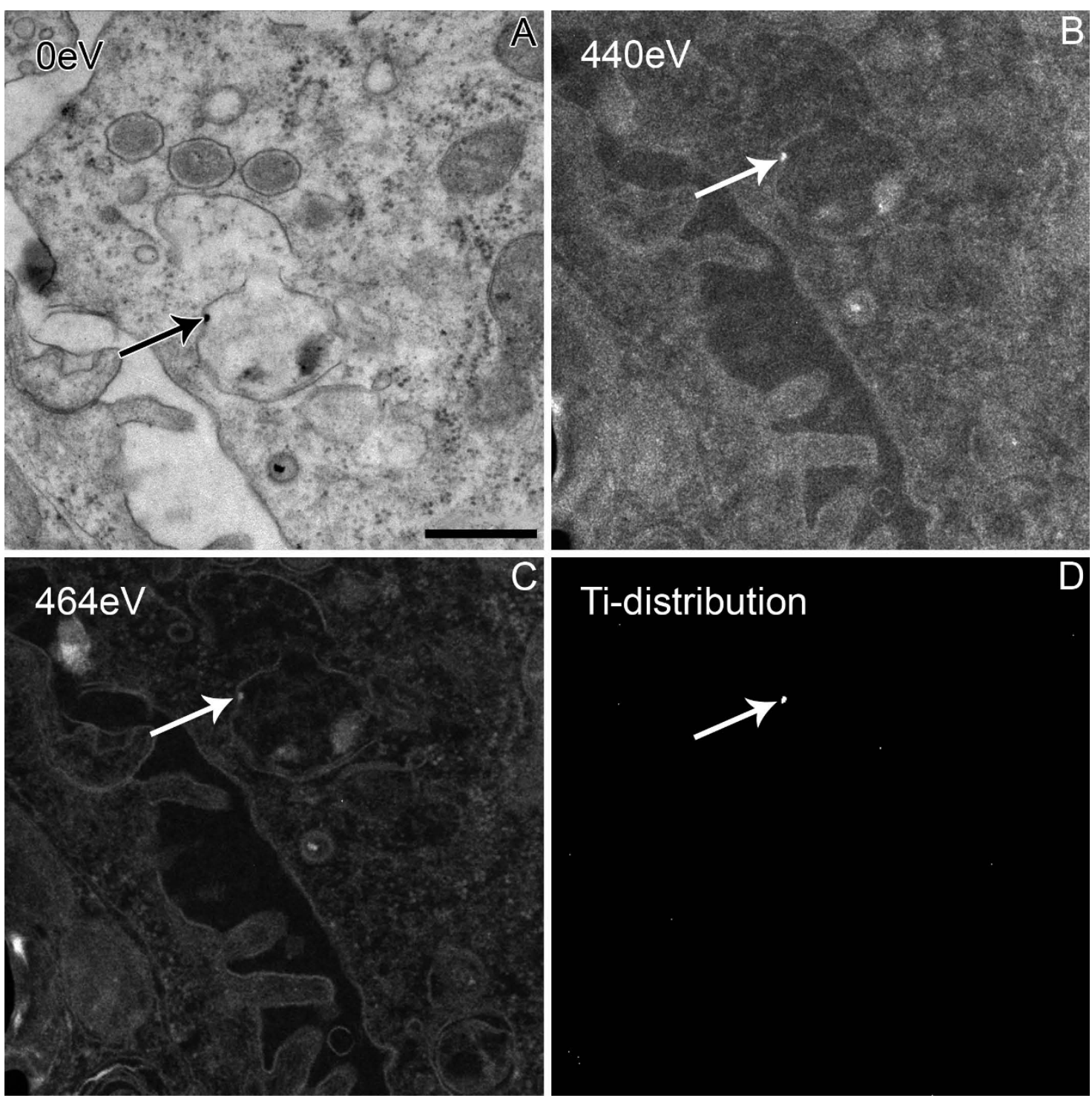

Figure 4 Elemental microanalysis of a particle in lung tissue by electron spectroscopic imaging (ESI, three window method), demonstrating that the nanoparticles (arrows) consists of titanium, adapted from [21]. The first image (A), taken at $0 \mathrm{eV}$, shows the structural details; it is slightly shifted as compared to the images used for elemental microanalyses (B-D). For elemental microanalysis, three images are taken: two below the element-specific edge in order to extrapolate a background image, at $\Delta \mathrm{E}=390 \mathrm{eV}(\mathrm{not}$ shown) and $\Delta \mathrm{E}=440 \mathrm{eV}$ (B), respectively, and one image within the maximum of the element specific signal at $\Delta E=464 \mathrm{eV}\left(\mathrm{L}_{2,3}\right.$ edge of titanium) (C). The net titanium signal (D) is calculated by subtraction of the extrapolated background image from the titanium specific signal. ESI images have reversed contrast as solely inelastically scattered electrons are used with an energy loss producing a dark field image. Hence, the obtained image reflects the titanium distribution in white pixels. Bar: $500 \mathrm{~nm}$.

and colleagues [32]. Therein, especially the methods for relative quantification of nanoparticles allowing between-group and within-group between-compartment comparisons are readily applicable and have been used already [e.g. [31,33,34]]. They are usually performed using particle transect counts on ultrathin sections. Methods for absolute quantification counts are performed in 3-dimensional space, using pairs of physical sections, the physical disector, or pairs of optical sections in a thick section, the optical disector (e.g. [35-37]). We have implemented this technique to count micrometer sized particles and airway macrophages in lungs by light microscopy (e.g. [25,38]). The use of (physical or optical) disectors for total number estimates of inhaled nanoparticles, however, is currently not practicable in electron microscopy, foremost because of the high magnification required for particle identification, but also because of the low number of particles that 


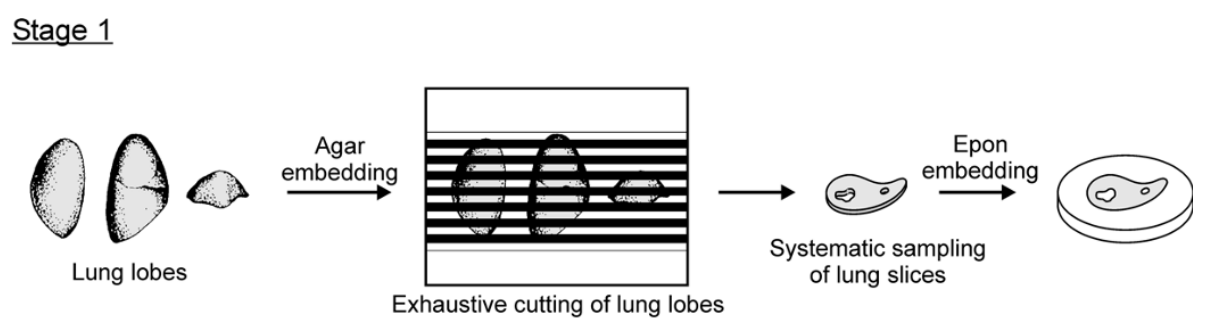

Stage 2

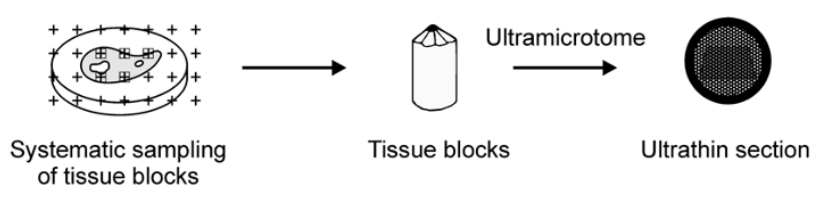

Stage 3

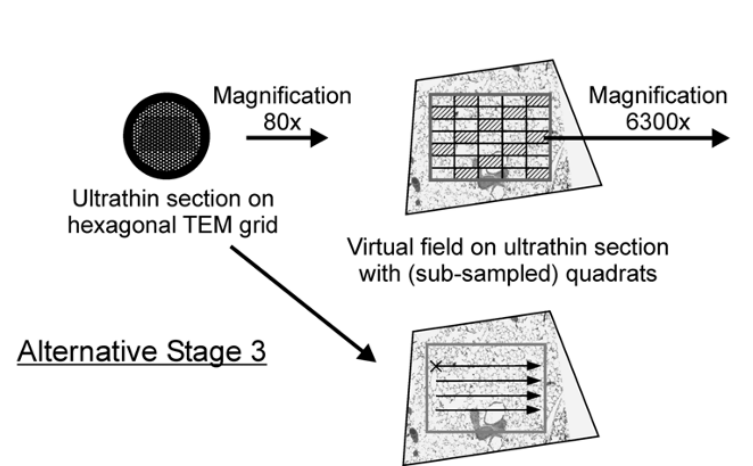

Systematic analysis of hexagonal fields from a random starting point $(x)$
Stage 4

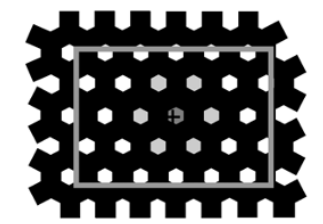

Sub-sampling of hexagonal fields for analysis from quadrat

Figure 5 Multistage tissue sampling design for EFTEM analysis of nanoparticles, adapted from [21]. Stage 1 - Lung slices: exhaustive cutting of agar embedded lung lobes (with random start) into equally thick slices [38], followed by systematic sampling of slices, e.g. every second (with random start) and Epon embedding. Stage 2 - Tissue blocks and ultrathin sections: systematic sampling (with random start) of tissue blocks from lung slices using a point counting test system and cutting of ultrathin $(\leq 50 \mathrm{~nm}$ ) sections, which are placed on 600-mesh hexagonal copper grids and stained with lead citrate and uranyl acetate. Stage 3 - Quadrats on ultrathin sections: generation of a virtual field, completely contained within the ultrathin section, at $80 \times$ magnification. Field subdivision into a predetermined number of uniform quadrats and systematic subsampling of quadrats thereof (marked in grey). Stage 4 - Fields for nanoparticle analysis: Subsampling of a group of seven adjacent fields, delimited by the hexagonal TEM grid bars, within each quadrat at 6300x magnification, using a point counting test system. Tissue analysis within these hexagonal fields for (i) the presence of particles with matching nanoparticle characteristics and (ii) particle localization within the compartments of interest. Stages 3 and 4 can equally be applied on ultrathin sections of cell pellets. Alternative to stages 3 and 4 - Fields for nanoparticle analysis are sampled by picking a random hexagonal field on the ultrathin section as starting point at 80x magnification. From there on systematic tissue analysis in horizontal and vertical direction, using the automated goniometer of the microscope.

penetrate into the lung tissue [26]. The latter is also the reason why electron tomography that allows the application of the advanced stereological tools described above can currently not be used in realistic inhalation studies.

\section{Particle deposition and biokinetics \\ Particle deposition and lung anatomy}

The mechanisms, the pattern and the efficiency of particle deposition in the respiratory tract largely depend on the aerodynamic or thermodynamic diameter of the inhaled particles (Figure 6). Nanoparticles deposit with high efficiency in the entire respiratory tract, from the head airways to the alveoli, due to diffusion. Therefore, only their thermodynamic diameter is relevant during inhalation; the aerodynamic diameter remains irrelevant, because sufficiently strong drag forces are absent.

The Human Respiratory Tract Model (HRTM) of the International Commission of Radiological Protection (ICRP) provides deposition data of inhaled particles from $1 \mathrm{~nm}$ to $10 \mu \mathrm{m}$ of healthy adult female and male human subjects, at different breathing patterns and physiological activities [39]. Data are given for the 


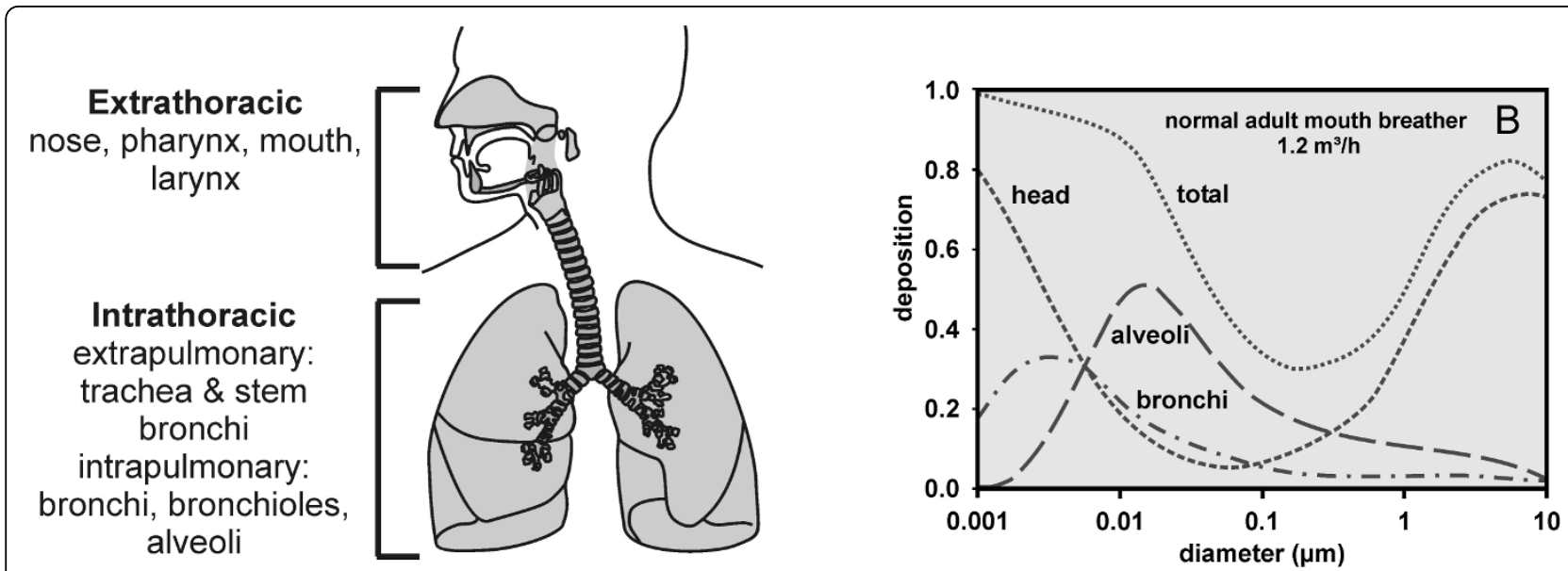

Figure 6 The respiratory tract $(A)$ and particle deposition in a normal adult mouth breathing male human subject at rest, as a function of particle size (B). Data of bronchi are the sum of the deposition in bronchi and bronchioles. Adapted from [105] and [39] and reprinted with permission from [21].

extrathoracic, the bronchiolar (i.e. sum of bronchi and bronchioles) and the alveolar regions. These data, which we recently discussed [40,41], represent a meta-analysis of the knowledge at the time of their publication; they are widely accepted and used in many applications. The deposition data given for children, however, were solely derived by applying numerical scaling factors to the data from adults. In fact, there is considerable lack of knowledge on the deposition in infants and children. Furthermore, there is ample evidence for significantly altered deposition of nanoparticles in patients with lung disease, due to changes in the breathing pattern and of fine pulmonary structures (for review [40-42]).

Despite considerable variations in airway and alveolar size and cellular composition, $\mathrm{n}$ as well as substantial interspecies differences, the airway and alveolar walls are built of the same basic structural elements (Figure 7A). In view of the inhaled particle these are: (i) the liquid lining layer consisting of the surfactant film at the air-liquid interface and the aqueous phase (periciliary layer and mucus) beneath it, (ii) the mobile cells, i.e. mainly resident airway and alveolar macrophages submersed in the aqueous phase; (iii) the highly differentiated epithelium with its basement membrane and (iv) the subepithelial connective tissue containing the blood and lymphatic vessels, and further cells of the immune system. The inner surface of the lungs functions as a physical, biochemical and immunological barrier, separating the outside from inside. It is also these structures deposited particles first interact with.

\section{Particle retention and relocation pathways within the lungs}

The retention of particles starts with their wetting and subsequent displacement from the air into the aqueous phase by surfactant (Figures 7B/C); regardless of shape, surface topography and surface free energy [43-46]. Though experimentally demonstrated yet for microparticles of $1-6 \mu \mathrm{m}$ in diameter and fibers, the same can be expected for nanoparticles, since this process becomes even more efficient with decreasing particle size.

In general, microparticles $(0.5-10 \mu \mathrm{m}$, see our definition in the Introduction) remain on the epithelial surface in airways and alveoli and are accessible to BAL, as experimentally best demonstrated in rodents $[47,48]$. Their retention time depends on the deposition site and on the interaction of the particles with the inner lung surface. It is short for particles deposited in conducting airways due to efficient mucociliary and cough clearance, but it increases with airway generation number, as a consequence of increasing pathway length and decreasing mucus velocity. While the retention of microparticles generally does not exceed $24-48 \mathrm{~h}$ in rodent airways, there is evidence for prolonged retention of microparticles in airways of dogs [49] and of both micro- and nanoparticles in small airways of humans [50,51], the probability being inversely correlated to particle size. In the latter studies, a maximum of long term retention of up to $80 \%$ was found for particles $\leq 100$ $\mathrm{nm}$. Further evidence for a correlation between geometric particle diameter and prolonged particle retention in airways was recently obtained from a study targeting $100 \mathrm{~nm}$ carbon particles to human airways by shallow aerosol bolus inhalation [42,51]. In this study only $25 \%$ of the nanoparticles were removed by mucociliary clearance within $24 \mathrm{~h}$, while $75 \%$ were retained for more than $48 \mathrm{~h}$. Possible explanations for these findings are that the particles were no longer accessible to mucociliary clearance either because they penetrated through the mucus deep into the periciliary phase $[43,46]$, or that they were deposited in areas with 

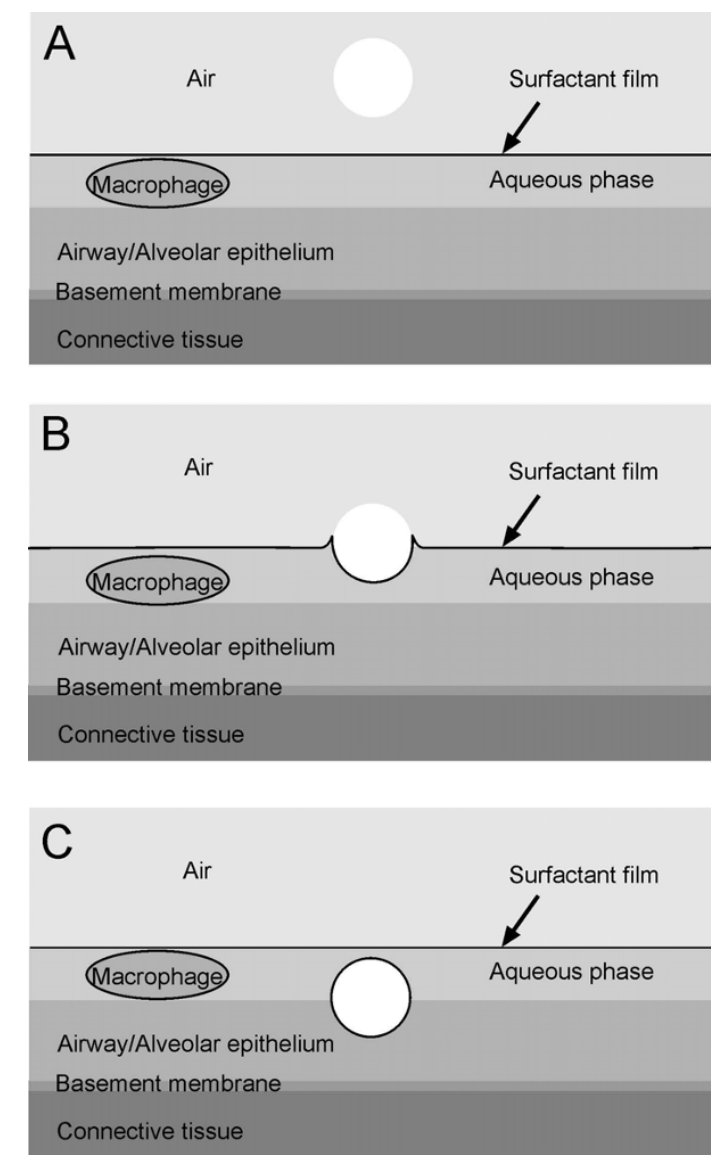

Figure 7 Components of the inner surface of the lungs $(A)$; particle deposition and immediate wetting (B) and complete displacement $(C)$ of the deposited particle (white sphere) into the lung lining layer by surfactant. Reprinted with permission from [21].

reduced lung lining layer. In both cases, further interaction of particles with cells of the inner lung surface, i.e. macrophages, dendritic and epithelial cells is furthered [52], and the probability for particle relocation beyond the epithelial barrier enhanced.

Well known and recognized is the interaction of particles with lung surface macrophages. As we discuss in detail in the subsequent section, phagocytic uptake of particles is a key factor for particle clearance in airways and alveoli, also contributing to particle retention. Evidence for relocation of microparticles to interstitial sites and long term retention was obtained from biokinetics and subsequent morphologic studies in dogs [50,53]. There are only few in vivo data of nanoparticles retained within the lung tissue. We found $20 \mathrm{~nm} \mathrm{TiO}_{2}$ nanoparticles, though a small fraction, to penetrate into epithelial cells and deeper into the lung tissue within only $1 \mathrm{~h}$ after aerosol inhalation in rats [31]. From this electron microscopic study, there was no evidence for substantial accumulation of nanoparticles in the lung tissue within $24 \mathrm{~h}$ post aerosol inhalation. Evidence for considerable particle relocation into the pulmonary tissue over a longer period of time, however, was obtained in a six month study in rats that had inhaled $20 \mathrm{~nm}$ iridium particles during $1 \mathrm{~h}[12,13]$. In this study, as shown in Table $1,46 \%$ of the nanoparticles were accessible to exhaustive BAL immediately after aerosol inhalation; most of them (78\%) were not associated with macrophages. At $24 \mathrm{~h}$ and later, only about $10 \%$ of the nanoparticles were accessible to BAL, and from $72 \mathrm{~h}$ on most of them (90\%) were associated with macrophages. It is not yet known by how much the material determines the extent of particle relocation into cells and beyond epithelial barriers. For clarification of the observed differences between $\mathrm{TiO}_{2}$ and iridium nanoparticles described above, additional studies of iridium nanoparticles at the individual particle level, i.e. by (EF) TEM, and of the biokinetics of adequately labeled $\mathrm{TiO}_{2}$ nanoparticles are required.

As a result of the relocation of particles from the lung surface into the pulmonary tissue, such particles may become accessible to lymphatic drainage and they may enter blood vessels favoring subsequent dissemination into secondary organs. Surprisingly, a rather small fraction of microparticles retained in the interstitial lung tissue in dogs was cleared to the hilar lymph nodes, and there was no detectable particle translocation into the blood circulation during the entire retention period $[50,53]$. Though not studied, macrophage mediated reappearance of microparticles on the lung surface for subsequent transport towards the larynx was suggested, as more than $90 \%$ of the microparticles were found to be associated with BAL macrophages at any time after inhalation. In our $24 \mathrm{~h}$ study with $\mathrm{TiO}_{2}$ nanoparticles in rats lymphatic drainage was not assessed and very few particles were found to have penetrated into the blood vessels [31]. Furthermore, in the above mentioned study with iridium in rats $[12,13]$ there was no noticeable accumulation of nanoparticles in tracheal lymph nodes and little translocation into the blood, as altogether about $10 \%$ of the deposited nanoparticles were found to be retained in all secondary target organs, the skeleton and soft tissue [54]. Instead, and as observed for microparticles retained in the interstitium of dog lungs, the long term retained iridium nanoparticles apparently re-appeared on the epithelium. And again, subsequent macrophage mediated clearance to the larynx is likely, since more than $90 \%$ of the iridium nanoparticles were associated with BAL macrophages at and beyond $72 \mathrm{~h}$ after aerosol inhalation.

\section{Particle transport towards the larynx Conducting airways}

The major pathway for particle clearance from conducting airways is by mucociliary transport. The transport 


\begin{tabular}{cccc}
\hline Time of BAL after aerosol inhalation $(\mathbf{h})$ & $\begin{array}{c}\text { Particle recovery by BAL } \\
\text { (\% lung retention) }\end{array}$ & $\begin{array}{c}\text { Particles associated with BAL macrophages } \\
\text { (\% lavaged nanoparticles) }\end{array}$ \\
\hline 0 & 46 & 22 \\
6 & 19 & 62 \\
24 & 11 & 70 \\
72 & 10 & 92 \\
\hline
\end{tabular}

rate depends on both the cilia and the lung lining layer; it is fastest in the central airways and gets slower with increasing airway generation (for review [50]).

In rodents, microparticles in airways are usually cleared within $24-48 \mathrm{~h}$ and the clearance of nanoparticles seems to be fast as well. Kinetic studies with iridium nanoparticles revealed a clearance of about $30 \%$ of the deposited particles within the first $24 \mathrm{~h}$ after aerosol inhalation (rat [11], mouse [55]). The experimental data in rats correspond rather well with theoretical ones [56]; free public software "Multipath Model of Particle Deposition, MPPD" is available for particle deposition and clearance estimates in humans and rats http://www. thehamner.org/mppd/helpfiles/index.htm. However, there is evidence that mucociliary clearance may not remove all particles from the lung surface, particularly in dogs and humans, resulting in prolonged particle retention, as we discussed in the previous section. These apparent differences between species have to be utterly considered when extrapolating rodent data to man. As mentioned also in the previous section, the mechanisms for prolonged retention and, hence, slower clearance of particles from airways remain unclear. Yet, prolonged retention favors accumulation of inhaled material within the tissue, i.e. leads to increased lung burden, which may be a factor for small airway cancer development. In fact, the HRTM model of the ICRP already included the element of prolonged airway retention.

Resident macrophages also contribute to the clearance of particles from conducting airways. Data from studies in hamsters with particles of $3-6 \mu \mathrm{m}$ in diameter and of different materials, showed an average uptake of $28 \%$ (SD $16 \%$ ) of particles deposited in airways by macrophages within less than $1 \mathrm{~h}$ after aerosol inhalation and of more than $80 \%$ of the remaining particles at $24 \mathrm{~h}$ [24]. From this study there was also evidence for rapid (mucociliary) clearance of macrophages with high particle loads.

\section{Respiratory bronchioles and alveoli}

Particle uptake by resident surface macrophages and further transport to the larynx is the predominant mechanism for particle clearance from the peripheral lungs. As in the conducting airways, the internalization of microparticles is rapid and essentially complete within $24 \mathrm{~h}[25,57,58]$.
The transport rate of microparticles, i.e. their clearance from the lungs varies between species; it is one order of magnitude lower in man, monkey, dog and guinea pigs than in rodents and sheep [50,59]. One anatomical feature of the lung, i.e. the number of generations of respiratory bronchioles correlates rather well with these observed species specific differences: rat, mouse, hamster and sheep have $0-2$ generations of respiratory bronchioles, whereas man, monkey and dog have $3-5$ [60]. There is one exception: the particle clearance rate is slow in guinea pigs, although they have only about one generation of respiratory bronchioles. Species specific differences in particle relocation from the surface into the lung tissue, as discussed in the previous section, may also contribute to the observed variations. Respective correlations can be deduced from experimental studies with microparticles, which are transported to the interstitium in human or canine lungs, but remain on the epithelium in rodent lungs (hamsters: $[48,61]$ ).

Effective surface macrophage mediated clearance rates have been found to be the same for micro- and nanoparticles in rodent lungs [13]. Hence, one could extrapolate from both lines of evidence that in human beings nanoparticles penetrate the lung epithelium for long term interstitial retention like the microparticles and consequently the clearance kinetics of nanoparticles is as slow as that of microparticles. The underlying mechanisms are not yet fully understood and presumably more complex. Note, however, that due to the very slow particle clearance kinetics in humans, with declining particle clearance rates over increasing retention time, an estimated fraction of $10-20 \%$ of insoluble particles will never be cleared out of the human lungs under physiological conditions [50]. In cases of very high particle exposure, like in smoking or in some occupational settings (mining, milling, etc.), the fraction of never-cleared particles may be substantially enhanced and associated with fibrotic pathogenesis.

We have recently assessed the clearance of inhaled 20 $\mathrm{nm} \mathrm{TiO}_{2}$ particles by surface macrophages at the individual particle level by EFTEM [26]. The data from this study in rats showed that surface macrophages do not efficiently phagocytose these nanoparticles but take them up rather sporadic and non-specific within the 
first $24 \mathrm{~h}$ after particle inhalation: (i) There was only about $0.1 \%$ of the $\mathrm{TiO}_{2}$ nanoparticles internalized by macrophages within $24 \mathrm{~h}$ after aerosol inhalation, compared to $>10 \%$ of microparticles that were phagocytosed already within $1 \mathrm{~h}$ [24] and $>80 \%$ within $24 \mathrm{~h}$ after aerosol inhalation $[38,57,58,62,63]$. (ii) As little as $0.2 \%$ and $1.7 \%$ of the BAL macrophage populations contained nanoparticles at $1 \mathrm{~h}$ and at $24 \mathrm{~h}$, respectively, after the aerosol inhalation, which is about two orders of magnitudes less than what was shown for $3-6 \mu \mathrm{m}$ particles of different materials $[24,25]$. (iii) $\mathrm{The} \mathrm{TiO}_{2}$ nanoparticles in BAL macrophages were not tightly enclosed by the vesicular membrane, as it is known from phagocytic uptake of microparticles. Instead, nanoparticles were located in large vesicles that mostly contained other material (Figure 8). This also points to a rather sporadic uptake of $\mathrm{TiO}_{2}$ nanoparticles by surface macrophages, maybe during the process of phagocytic uptake of other material. Hence, there is evidence from these studies that, at least within the first $24 \mathrm{~h}$ after aerosol inhalation, nanoparticles bypass the most important clearance mechanisms for particles deposited in the alveoli, namely phagocytic uptake by surface macrophages. Consequently, the probability of uptake by epithelial cells and/or relocation through the thin epithelial barrier increases for nanoparticles.

Despite all the variations discussed above, the main pathway for particle clearance in airways and alveoli, for free and phagocytosed particles, for micro- and nanoparticles, is towards the larynx. Even particles that were relocated into the underlying interstitium seem to reappear again on the lung surface to be cleared this way.

\section{Other particle clearance pathways}

Particle clearance via the lymphatic system

Particle clearance through lymphatic drainage may be expected in lungs where significant particle retention in the interstitial space has been shown, i.e. microparticles in dogs and iridium nanoparticles in rats. However, in

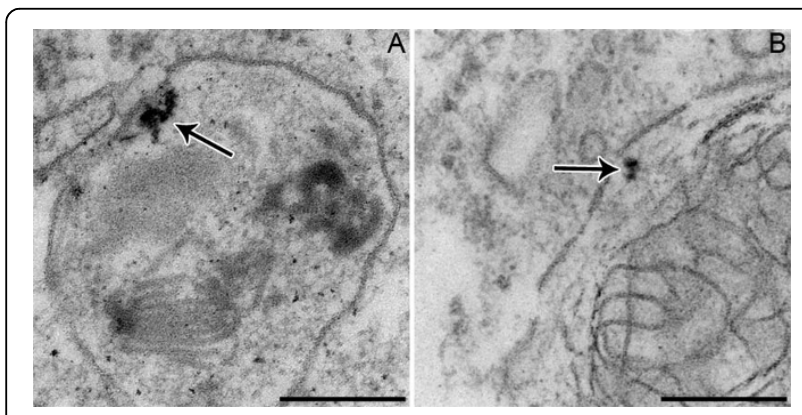

Figure 8 TEM micrographs (A) and (B) of inhaled $\mathrm{TiO}_{2}$ nanoparticles (arrows) located in large phagolysosomes, which contain other phagocytosed material, in mouse surface macrophages. Bars: $200 \mathrm{~nm}$. dogs only a small, intersubject variable fraction of 1 $5 \%$ of deposited microparticles was found to be drained to the regional lymph nodes under physiological conditions $[50,64]$. Though there are no human long term lymphatic clearance data available, we expect essentially the same fate for microparticles as in dog lungs, because of the striking similarities of particle clearance kinetics in these two species. There was also no noticeable iridium nanoparticles accumulation found in tracheal lymph nodes of rats $[12,13]$.

Still unclear is the role of bronchus associated lymphatic tissue (BALT) by which particles would find their way back to the airway epithelium, via particle drainage into the lymphatic vessels and the blood circulation, as it was hypothesized many years ago [65-67].

\section{Particle transport from the interstitium onto the epithelial} surface

As discussed above, there is evidence for re-appearance of microparticles on the lung epithelium in dogs and humans, and of nanoparticles in rodents, because the most prominent clearance pathways of long term (in the interstitium) retained particles were shown to be surface macrophage mediated and directed towards the larynx (dogs [53], rats [13]). This clearance pathway is obsolete in rodents, which have negligible interstitial retention of microparticles $[48,61]$. So far there are no human or large species data available on the long term retention and clearance of insoluble nanoparticles from the peripheral lungs. The re-appearance of nanoparticles on the lung epithelium from the interstitium is likely to be macrophage mediated. As discussed above, we cannot yet exclude that particles may also re-appear on the lung epithelium as a consequence of their release into the lymphatic vessels from BALT [65-67].

\section{Particle translocation to the blood and accumulation in secondary target organs}

For more than a decade, epidemiological studies have indicated associations between exposure to increased concentrations of ambient fine and ultrafine particles and adverse health effects in susceptible individuals $[1,4,5,68]$. Cardiovascular effects observed in these studies triggered the discussion on increased transport of inhaled ultrafine particles from the epithelial surface towards the blood circulation and subsequently to target organs, like the heart, liver and brain, eventually adversely affecting the functions of these organs [69].

From the latter review, nanoparticles are apparently transported across membranes with hardly any restraint, which has not been reported for microparticles. As a mechanism, complex formation of nanoparticles with lung lining layer proteins as such that this complex acts like a ferry boat for nanoparticles is conceivable. Microparticles would be excluded from this transport because of their larger size [70-72]. In addition, since 
microparticles are rapidly phagocytosed by lung surface macrophages, they are only shortly available for protein mediated transport. Surface modifications of nanoparticles are currently intensely studied in nanomedicine aiming at managing specific biokinetic behaviors of nanoparticles to distinctively target organs for diagnostic as well as therapeutic use [73]. As an example, drug delivery to the central nervous system via circulating nanoparticles requires surface modifications allowing receptor mediated nanoparticle translocation across the blood-brain barrier. Apolipoprotein-E coating of nanoparticles for LDL receptor mediated endocytosis in brain capillaries has been discussed [74-76]. Such highly desirable properties of nanoparticles must be carefully weighed against potential adverse cellular responses to targeted drug delivery by nanoparticles; a rigorous risk assessment is mandatory.

Nanoparticles not only offer a much larger surface area to be modified than microparticles of the same mass, but their larger number allows their dispersion into many more cells. For instance, a particle mass of 100 ng corresponds to only $2.4 \times 10^{4}$ particles (spheres of unit density) of $2 \mu \mathrm{m}$ in diameter, but to $2.4 \times 10^{10}$ particles of 20 $\mathrm{nm}$, or to $2.4 \times 10^{13}$ particles of $2 \mathrm{~nm}$. Note that $20 \mathrm{~nm}$ particles comprise a major fraction of the number concentration of ambient aerosol particles [77] and that 2 to $10 \mathrm{~nm}$ particles are the primary particles originating from many combustion processes of which aggregated ambient ultrafine particles are made of.

Assuming that $100 \mathrm{ng}$ of particles have accumulated in a secondary target organ like the heart or the brain, this would usually not be considered to be of any toxicological relevance for low toxicity particles. This is particularly true for the low particle number in the entire organ, when particles are $2 \mu \mathrm{m}$ in diameter. However, if they are $2 \mathrm{~nm}$ particles, they exceed the number of cells in the organ easily by a factor of thousand (cell estimate is based on a $100 \mathrm{~g}$ organ and a cell volume of $4.2 \times 10^{-}$ ${ }^{9} \mathrm{~cm}^{3}$ corresponding to a cell of $20 \mu \mathrm{m}$ in diameter). This enhances the probability of inducing adverse effects, although other factors like the subcellular localization of the nanoparticles, their chemistry and surface characteristics like surface proportional numbers of biochemically reactive centers are contributing as well.

There is plentiful literature on nanoparticle-cell interaction studies in vitro, however, the number of particles per cell was mostly not estimated but only the total mass added to the cell cultures is reported. In addition, rough estimates indicate that in most of these studies the nanoparticles to cell ratio was far beyond 1000:1, which largely exceeds any realistic dose in vivo. In many in vitro studies, particles are applied in doses of $1-100$ $\mu \mathrm{g}$ per $10^{5}$ cells. Assuming the application of the lowest dose of $1 \mu \mathrm{g}$ particles per $10^{5}$ cells and the use of spherical nanoparticles of unit density and a size of 50 $\mathrm{nm}, 2 \times 10^{5}$ nanoparticles per cell, or $2 \times 10^{10}$ nanoparticles per $10^{5}$ cells, are applied. However, the effective dose per cell is very difficult to estimate, since these nanoparticles will not precipitate in the cell culture medium because of their minimal mass, but move by Brownian motion (diffusion), which is a non-directed motion. In addition, particle diffusion favours agglomeration to larger particle structures, which will then precipitate. By the time they do so, the particle characteristics, i.e. size distribution and concentration have obviously massively changed.

To estimate exposure conditions in vivo, we may assume an inhaled daily air volume of $15 \mathrm{~m}^{3}$ for a healthy, adult, moderately active individual [39], a number concentration of ambient air particles of $3 \times 10^{4}$ / $\mathrm{cm}^{3}$, whereof $80-90 \%$ are nanoparticles [77], and a particle deposition fraction of 0.3 [39]. The first exposure estimate results in $1.4 \times 10^{11}$ nanoparticles being deposited per day or $6 \times 10^{9}$ particles deposited per hour. Even if particle number concentrations are higher, there is a maximal possible daily deposition of nanoparticles because of aerosol-physical limitations mostly due to diffusional coagulation. It is not possible to maintain the number concentration of nanoparticles aerosols above 1 $\times 10^{6} / \mathrm{cm}^{3}$ for more than several minutes under normal ambient conditions. Hence, under such conditions maximally $2 \times 10^{13}$ nanoparticles per day or $6 \times 10^{11} / \mathrm{cm}^{3}$ per hour can be inhaled by an adult human. To estimate the ratio of nanoparticles per cell in vivo, we focus on the lung periphery, which is by far the largest compartment for nanoparticle deposition. We assume the alveolar surface of about $140^{2} \mathrm{~m}$ in humans to consist of $2 \times$ $10^{10}$ epithelial type I cells and $3 \times 10^{10}$ epithelial type II cells, and to contain $6 \times 10^{9}$ alveolar macrophages [78]. Hence, for breathing of ambient aerosols, on average 6 nanoparticles will be daily deposited per cell in the alveolar region. Maximally, but not realistic, at the highest possible nanoparticles aerosol number concentration of $1 \times 10^{6} / \mathrm{cm}^{3}$, an alveolar surface cell will receive on average 120 nanoparticles per hour. Even if we consider a maximum factor of 20 for inhomogeneous deposition beyond an otherwise rather homogeneous diffusional deposition in the peripheral lungs, the nanoparticle dose to some surface cells may increase by this factor at most.

For in vitro studies to become more relevant for assessing health effects by inhaled particles the nanoparticle dose per cell should reflect real exposure conditions [79].

\section{Experimental studies on nanoparticle biokinetics}

Human studies

Comprehensive biokinetics analysis of nanoparticles accumulation and retention in organs and tissues is not 
feasible in humans; because of ethical, but also technical reasons due to limiting resolution of existing imaging detection systems from outside the body or for body fluid samples.

So far, there is no evidence for a translocated nanoparticle mass fraction of more than $1 \%$ of the dose delivered to the lungs from reliable studies in humans [42,80-83]. However, there is indirect evidence of nanoparticle translocation in humans from recent inhalation studies in healthy subjects with diluted Diesel exhaust, which was found to impair the regulation of the vascular tone and fibrinolysis [84]. In addition, in a similar study, spontaneous alterations of electroencephalogram (EEG) signals in the frontal cortex were observed during and up to $1 \mathrm{~h}$ after exposure to Diesel exhaust [85]. From these studies it is not clear, whether the observed effects were initiated by translocated nanoparticles or by mediators released from the lungs in response to interactions with deposited nanoparticles.

Until now, histopathology revealed substantial particle loads in secondary target organs only after long term and massive exposure to microparticles; e.g. tar accumulation leading to increased blackening of lungs in smokers, particle or fiber accumulation in the liver and other organs of the reticulo-endothelial system in coal miners and asbestos workers [86,87]. Thereby, particle transport from the interstitium to the lymphatic system and further into the blood circulation was assumed. Similarly, in overload conditions translocation and accumulation of microparticles particularly in reticuloendothelial organs were observed in experimental animals (dogs [88], rodents reviewed by [89]).

Animal studies

There is evidence for translocation of gold, silver, $\mathrm{TiO}_{2}$, polystyrene and carbon nanoparticles in the size range of $5-100 \mathrm{~nm}$ across the air-blood barrier from animal experiments. Either, nanoparticles were found in the blood circulation $[31,90]$ and in secondary target organs [11-13,91-94], or thrombogenic effects were observed [95-97]. However, it still remains unclear, whether the translocated particle fractions exceeded $5 \%$ of the delivered lung dose (see also [41,98]). Recently, Chen and colleagues [99] reported an estimated translocated fraction of $1-2 \%$ for 50 and $200 \mathrm{~nm}$ polystyrene particles.

\section{Quantitative assessment of nanoparticle translocation}

Quantitative particle biokinetics as described in the Methods section allows the precise estimate of total and organ specific translocated nanoparticle fractions. Such data are currently available for:

- Inhaled iridium nanoparticles, 20 and $80 \mathrm{~nm}$ in diameter, in rats and mice [11-13]

- Inhaled carbon nanoparticles, $25 \mathrm{~nm}$ in diameter, spiked with radio-labeled primary iridium nanoparticles in rats [54]
- Instilled gold nanoparticles, 1.4 and $18 \mathrm{~nm}$ in diameter, in rats $[94,100]$.

From the inhalation studies with iridium nanoparticles it became clear that such particles accumulate not only in secondary target organs but also in soft (connective) tissue and skeletal bone including bone marrow. In these studies, accumulation of $20 \mathrm{~nm}$ particles in all secondary target organs (liver, spleen, kidneys, heart, brain, reproductive organs) was in the range of $1-2 \%$ of the deposited dose at $24 \mathrm{~h}$ after administration. A similar fraction was found in the skeleton and up to $5 \%$ in the soft tissue. Hence, the total translocated fraction of nanoparticles reached just about 10\% [54]. Furthermore, $20 \mathrm{~nm}$ iridium nanoparticles were poorly cleared from secondary target organs such that six months after a single one hour inhalation exposure, the total fraction of nanoparticles in all secondary target organs was still close to $0.1 \%$ of those initially deposited in the lungs, and all organs studied still contained nanoparticles $[12,13]$. Unfortunately, there are no further data on long term translocation of nanoparticles yet.

Even in the fetuses of pregnant rats in their third trimester, small but detectable fractions of translocated nanoparticles were registered [94].

\section{Particle characteristics}

Size

There is evidence from experimental studies that the translocation and accumulation of nanoparticles in secondary target organs depend on particle size; i.e. inhaled $80 \mathrm{~nm}$ iridium particles were shown to translocate about one order of magnitude less than the $20 \mathrm{~nm}$ ones, including accumulation in the skeleton and soft tissue $[11,54]$. Additionally, significant differences in the translocation and accumulation between $1.4 \mathrm{~nm}$ and $18 \mathrm{~nm}$ gold nanoparticles have been observed, with total translocated fractions of $8 \%$ and $0.2 \%$, respectively, at $24 \mathrm{~h}$ after their intratracheal instillation [100]; both size categories were found in all secondary target organs investigated.

Material

Consequences of different materials on nanoparticle translocation and $24 \mathrm{~h}$ accumulation in secondary organs can be derived from inhalation studies with 20 $\mathrm{nm}$ iridium and $25 \mathrm{~nm}$ carbon nanoparticles. The fraction of carbon was significantly, 5 - 10 times lower than that of iridium (except in the liver) in any of the secondary target organs studied as well as in the skeleton or soft tissue. Note that both particle types are chain agglomerates made up of either 2 to $5 \mathrm{~nm}$ iridium or 5 to $10 \mathrm{~nm}$ carbon primary particles. Caution is required when these data are compared with those of $18 \mathrm{~nm}$ gold of similar size: there is not only the material difference, but gold nanoparticles are spherical and have a smooth surface. In addition, particle administration to the lungs 
was different (inhalation versus instillation). Yet, the total difference of almost $10 \%$ of translocated iridium and about $2 \%$ carbon chain agglomerates compared to $0.2 \%$ of the spherical gold nanoparticles within $24 \mathrm{~h}$ is striking, when considering particle material dependence only. There are more quantitative data required to better understand how particle materials influence biokinetics.

\section{Dosimetry models for risk assessment}

Experimental data help to develop and optimize mathematical models to predict the risk from inhaled particles. Kuempel and colleagues [101] showed reasonably good agreement between observed and predicted retained lung burden of poorly soluble fine and ultrafine particles in chronically exposed rats using dosimetry models. In addition, dosimetry models were further optimized to fit human data [102]. Thereby, the best fitting model was the one that included interstitionalization of particles, which is in accordance to the evidence obtained from experimental studies in humans. Such models can also be extended to include translocation of particles to secondary organs or differences in particle characteristics $[103,104]$.

\section{Summary remarks on nanoparticle translocation across the air-blood-barrier}

Besides the discussed importance of size and material, other particle characteristics such as the surface charge (zeta potential) and surface structures are very likely to influence nanoparticle biokinetics. They determine the interactions of nanoparticles with proteins and cellular components and thereby the mechanisms for particle translocation and accumulation in extra-pulmonary organs. However, it needs to be emphasized that according to current knowledge, nanoparticles translocation and accumulation in extra-pulmonary organs is a minor clearance pathway for nanoparticles from the lungs compared to (long term) macrophage mediated nanoparticle clearance towards the larynx. Yet, while the latter pathway leads to particle excretion via the gastrointestinal tract, nanoparticle translocation into the blood circulation systemically distributes nanoparticles and allows access to e.g. the cardio-vascular, the central-nervous and the reticulo-endothelial, i.e. the immune systems. Despite potential toxicological consequences for the organism when nanoparticles interact with these organ systems, it is still unknown whether it is the translocated nanoparticles that cause the epidemiologically established adverse effects. Particularly, it remains to be shown whether chronic exposure leads to sufficiently high nanoparticle doses to trigger or mediate responses leading to initiation and/or progression of disease. In addition, the release of mediators into the blood circulation needs thorough investigations: these mediators may be triggered or modulated by the well-known oxidative stress and pro-inflammatory responses to nanoparticles. Yet, even the importance of the dose metric is still debated. If nanoparticle mass is the effect determining metric, it appears very unlikely that sufficiently high doses in extra-pulmonary organs can be reached by inhalation. However, if nanoparticle number and (biochemically reactive) surface are the effect determining metrics, chronic exposure to nanoparticles may well be a health hazard; particularly, in susceptible individuals such as infants, the elderly and individuals with pre-existing cardiovascular and lung diseases.

Furthermore, the interaction of nanoparticles with the organism has to be studied at cellular and molecular levels, in lungs as well as in those secondary target organs which receive sufficiently high doses. Microscopic analyses of such organs from animal inhalation experiments may provide more detailed information about possible pathways responsible for (adverse) effects. It will be important to know which tissues, cells and/or subcellular compartments nanoparticles interact with and what particle properties are crucial for these interactions. Unrestricted crossing of the cellular membranes by nanoparticles facilitates not only their translocation into basically any organ but also into cells and subcellular compartment.

While unexpected nanoparticle access to secondary target organs at non negligible doses on a macroscopic scale as well as unexpected nanoparticle access to parenchymal and immune cells and to their subcellular structures like mitochondria and nuclei may result in adverse health effects, these interactions and pathways provide unforeseeable opportunities in the design of nanoparticles for diagnostic or therapeutic medical use in the new field of Nanomedicine.

\section{Abbreviations}

AA-MS: atomic absorption mass spectroscopy; BAL: bronchoalveolar lavage; BALT: bronchus associated lymphoid tissue; EEG: electroencephalogram; EFTEM: energy filtering transmission electron microscopy; ESI: electron spectroscopic imaging; HRTM: human respiratory tract model; ICP-MS: inductively coupled plasma mass spectroscopy; ICRP: international commission of radiological protection; TEM: transmission electron microscopy; $\mathrm{TiO}_{2}$ : titanium dioxide.

\section{Acknowledgements}

This work was supported in part by EU FP6 PARTICLE_RISK 012912 (NEST), U. S. National Institutes of Health grant HL070542, the German Research Foundation FOR 627 and SPP1313, the Swiss National Science Foundation grants 3200B0-105419 and 310030-120763, and the Swiss Society for Cystic Fibrosis. We acknowledge the contributions of all our colleagues to the reviewed research work. For this manuscript we acknowledge the microscopic and technical contributions by M. Casaulta, B. Krieger, B. Kupferschmid and C. Wigge.

\section{Author details}

${ }^{1}$ Institute of Anatomy, University of Bern, Baltzerstrasse 2, CH-3000 Bern 9 Switzerland. ${ }^{2}$ Comprehensive Pneumology Center, Institute of Lung Biology and Disease and Focus-Network Nanoparticles and Health, Helmholtz Center 
Munich, Munich, Germany. ${ }^{3}$ German Research Center for Environmental Health, Ingolstaedter Landstrasse 1, D-85764 Neuherberg/Munich, Germany.

\section{Authors' contributions}

MG was responsible for the design and realization of the studies at the microscopic level. WK was responsible for all inhalation studies and for the design and realization of the studies at the macroscopic level. Both authors prepared the manuscript and approved the final version.

\section{Competing interests}

The authors declare that they have no competing interests.

Received: 10 August 2009

Accepted: 20 January 2010 Published: 20 January 2010

\section{References}

1. Ibald-Mulli A, Wichmann HE, Kreyling W, Peters A: Epidemiological evidence on health effects of ultrafine particles. J Aerosol Med 2002, 15:189-201.

2. Laden F, Neas LM, Dockery DW, Schwartz J: Association of fine particulate matter from different sources with daily mortality in six U.S. cities. Environ Health Perspect 2000, 108:941-947.

3. Laden F, Schwartz J, Speizer FE, Dockery DW: Reduction in fine particulate air pollution and mortality: Extended follow-up of the Harvard Six Cities study. Am J Respir Crit Care Med 2006, 173:667-672

4. Pope CA III: Air pollution and health - Good news and bad. N Engl J Med 2004, 351:1132-1134

5. Schulz H, Harder V, Ibald-Mulli A, Khandoga A, Koenig W, Krombach F Radykewicz R, Stampfl A, Thorand B, Peters A: Cardiovascular effects of fine and ultrafine particles. J Aerosol Med 2005, 18:1-24.

6. Rytting E, Nguyen J, Wang X, Kissel T: Biodegradable polymeric nanocarriers for pulmonary drug delivery. Expert Opin Drug Deliv 2008, 5:629-639.

7. Duncan R: Polymer conjugates as anticancer nanomedicines. Nat Rev Cancer 2006, 6:688-701.

8. Ferin J, Oberdörster G, Penney DP: Pulmonary retention of ultrafine and fine particles in rats. Am J Respir Cell Mol Biol 1992, 6:535-542.

9. SCENIHR (Scientific Committee on Emerging and Newly Identified Health Risks), European Commission. Risk Assessment of Products of Nanotechnologies. http://ec.europa.eu/health/ph_risk/risk_en.htm.

10. Kuempel ED, Tran CL, Castranova V, Bailer AJ: Lung dosimetry and risk assessment of nanoparticles: evaluating and extending current models in rats and humans. Inhal Toxicol 2006, 18:717-724.

11. Kreyling WG, Semmler M, Erbe F, Mayer P, Takenaka S, Schulz H: Translocation of ultrafine insoluble iridium particles from lung epithelium to extrapulmonary organs is size dependent but very low. $J$ Toxicol Environ Health 2002, 65:1513-1530.

12. Semmler M, Seitz J, Erbe F, Mayer P, Heyder J, Oberdörster G, Kreyling WG Long-term clearance kinetics of inhaled ultrafine insoluble iridium particles from the rat lung, including transient translocation into secondary organs. Inhal Toxicol 2004, 16:453-459.

13. Semmler-Behnke M, Takenaka S, Fertsch S, Wenk A, Seitz J, Mayer P, Oberdörster G, Kreyling WG: Efficient elimination of inhaled nanoparticles from the alveolar region: Evidence for interstitial uptake and subsequent reentrainment onto airways epithelia. Environ Health Perspect 2007, 115:728-733.

14. Weibel ER: Morphometric and stereological methods in respiratory physiology including fixation techniques. Techniques in the life sciences Ireland: Elsevier Scientific PublishersOtis AB 1984, 1-35.

15. Brain JD, Gehr $P$, Kavet Rl: The importance of the fixation method. Am Rev Respir Dis 1984, 129:823-826.

16. Im Hof V, Scheuch G, Geiser M, Gebhard J, Gehr P, Heyder J: Techniques for the determination of particle deposition in lungs of hamsters. $J$ Aerosol Med 1989, 2:247-259.

17. Geiser M, Im Hof V, Siegenthaler W, Grunder R, Gehr P: Ultrastructure of the extracellular lining layer in hamster airways: Is there a two-phase system?. Micr Res Techn 1997, 36:428-437.

18. Gil J, Weibel ER: Extracellular lining of bronchioles after perfusion-fixation of rat lungs for electron microscopy. Anat Rec 1971, 169:185-200.
19. Hulbert WC, Forster BB, Laird W, Pihl CE, Walker DC: An improved method for fixation of the respiratory epithelial surface with the mucous and surfactant layers. Lab Invest 1982, 47:354-363.

20. Yoneda K: Mucous blanket of rat bronchus. Am Rev Respir Dis 1976, 114:837-842.

21. Kreyling WG, Geiser M: Dosimetry of Inhaled Nanoparticles. Nanoparticles in Medicine and Environment, Inhalation and Health Effects Springer BerlinMarijnissen JC, Gradon L 2009, 145-171.

22. Sims DE, Westfall JA, Kiorpes AL, Horne MM: Preservation of tracheal mucus by nonaqueous fixative. Biotech Histochem 1991, 66:173-180.

23. Thurston RJ, Hess RA, Kilburn KH, McKenzie WN: Ultrastructure of lungs fixed in inflation using a new osmium-fluorocarbon technique. $J$ Ultrastruct Res 1976, 56:39-47.

24. Geiser M: Morphological aspects of particle uptake by lung phagocytes. Micr Res Tech 2002, 57:512-522.

25. Geiser M, Baumann M, Cruz-Orive LM, Im Hof V, Waber U, Gehr P: The effect of particle inhalation on macrophage number and phagocytic activity in the intrapulmonary conducting airways of hamsters. Am J Respir Cell Mol Biol 1994, 10:594-603.

26. Geiser M, Casaulta M, Kupferschmid B, Schulz H, Semmler-Behnke M, Kreyling W: The role of macrophages in the clearance of inhaled ultrafine titanium dioxide particles. Am J Respir Cell Mol Biol 2008, 38:371-376.

27. Geiser M, Serra AL, Baumann M, Im Hof V, Gehr P: Efficiency of airway macrophage recovery by bronchoalveolar lavage in hamsters: a stereological approach. Europ Respir J 1995, 8:1712-1718.

28. Kapp N, Kreyling W, Schulz H, Im Hof V, Semmler M, Gehr P, Geiser M Identification of inhaled ultrafine titanium oxide particles by analytical electron microscopy in rat lungs. Microsc Res Techn 2004, 63:298-305.

29. Howard CV, Reed M: Unbiased Stereology: Three-Dimensional Measurement in Microscopy Oxford: Bios Scientific Publications, 22005.

30. Cruz-Orive LM, Weibel ER: Sampling designs for stereology. J Microsc 1981, 122:235-257.

31. Geiser M, Rothen-Rutishauser B, Kapp N, Schürch S, Kreyling W, Schulz H, Semmler M, Im Hof V, Heyder J, Gehr P: Ultrafine particles cross cellular membranes by non-phagocytic mechanisms in lungs and in cultured cells. Environ Health Perspect 2005, 113:1555-1560.

32. Mayhew TM, Mühlfeld C, Vanhecke $D$, Ochs M: A review of recent methods for efficiently quantifying immunogold and other nanoparticles using TEM sections through cells, tissues and organs. Ann Anat 2009, 191(2):153-170.

33. Mühlfeld C, Geiser M, Kapp N, Gehr P, Rothen-Rutishauser B: Re-evaluation of pulmonary titanium dioxide nanoparticle distribution using the "relative deposition index": evidence for clearance through microvasculature. Particle Fibre Toxicol 2007, 4(7):1-8.

34. Mühlfeld C, Mayhew TM, Gehr P, Rothen-Rutishauser B: A novel quantitative method for analysing the distributions of nanoparticles between different tissue and intracellular compartments. J Aerosol Med 2007, 20:395-407.

35. Cruz-Orive LM, Geiser M: Estimation of particle number by stereology: an update. J Aerosol Med 2004, 17:197-212.

36. West MJ, Østergaard K, Andreassen OA, Finsen B: Estimation of the number of somatostatin neurons in the striatum: an in situ hybridization study using the optical fractionator method. J Comp Neurol 1996, 370:11-22.

37. Sterio DC: The unbiased estimation of number and sizes of arbitrary particles using the disector. J Microsc 1984, 134:127-136.

38. Geiser M, Cruz-Orive LM, Im Hof V, Gehr P: Assessment of particle retention and clearance in the intrapulmonary airways of hamster lungs with the fractionator. J Microsc 1990, 160:75-88.

39. ICRP Publication 66: Human respiratory tract model for radiological protection. A report of a Task Group of the International Commission on Radiological Protection. Ann ICRP 1994, 24(1-3):1-482.

40. Kreyling WG, Semmler-Behnke M, Möller W: Ultrafine particle-lung interactions: does size matter?. J Aerosol Med 2006, 19:74-83.

41. Kreyling WG, Semmler-Behnke M, Moeller W: Health implications of nanoparticles. J Nanopart Res 2006, 8:543-562.

42. Möller W, Felten K, Sommerer K, Scheuch G, Meyer G, Meyer P, Haussinger K, Kreyling WG: Deposition, retention, and translocation of ultrafine particles from the central airways and lung periphery. Am J Resp Crit Care Med 2008, 177:426-432. 
43. Gehr $P$, Schürch $S$, Berthiaume $Y$, Im Hof V, Geiser M: Particle retention in airways by surfactant. J Aerosol Med 1990, 3:27-43.

44. Geiser M, Matter M, Maye I, Im Hof V, Gehr P, Schürch S: Influence of airspace geometry and surfactant on the retention of man-made vitreous fibers (MMVF 10a). Environ Health Perspect 2003, 111:895-901.

45. Geiser M, Schürch S, Gehr P: Influence of surface chemistry and topography of particles on their immersion into the lung's surface-lining layer. J Appl Physiol 2003, 94:1793-1801.

46. Schürch S, Gehr P, Im Hof V, Geiser M, Green F: Surfactant displaces particles toward the epithelium in airways and alveoli. Respir Physiol 1990, 80:17-32.

47. Lehnert BE, Valdez YE, Tietjen GL: Alveolar macrophage-particle relationships during lung clearance. Am J Respir Cell Mol Biol 1989, 1:145-154.

48. Ellender M, Hodgson A, Wood KL, Moody JC: Effect of bronchopulmonary lavage on lung retention and clearance of particulate material in hamsters. Environ Health Perspect 1992, 97:209-213.

49. Kreyling WG, Blanchard JD, Godleski JJ, Haeussermann S, Heyder J, Hutzler P, Schulz H, Sweeney TD, Takenaka S, Ziesenis A: Anatomic localization of 24- and 96-h particle retention in canine airways. J Appl Physiol 1999, 87:269-284.

50. Kreyling W, Scheuch G: Clearance of particles deposited in the lungs. Particle Lung Interactions New York: Marcel DekkerHeyder J, Gehr P 2000, 323-376.

51. Möller W, Kreyling WG, Schmid O, Semmler-Behnke M, Schulz H: Deposition, Retention and Clearance, and Translocation of Inhaled Fine and Nano-Particles in the Respiratory Tract (Chapter 5). Particle-Lung Interactions Informa Healthcare USA, New YorkGehr P, Mühlfeld C, RothenRutishauser B, Blank F, Second 2009, 79-107.

52. Blank F, Rothen-Rutishauser B, Gehr P: Dendritic cells and macrophages form a transepithelial network against foreign particulate antigens. Am J Respir Cell Mol Biol 2007, 36:669-677.

53. Kreyling WG, Takenaka S, Schumann G, Ziesenis A: Particles are predominantly transported from the canine epithelium towards the interstitial spaces and not to larynx! Analogy to human lungs?. Am J Respir Crit Care Med 2001, 163:A166.

54. Kreyling WG, Semmler-Behnke M, Seitz J, Scymczak W, Wenk A, Mayer P, Takenaka S, Oberdörster G: Size and material dependency of translocation of inhaled iridium or carbon nanoparticles from the lungs of rats to blood. Inhal Toxicol 2009, 21(S1):55-60.

55. Alessandrini F, Semmler-Behnke M, Jakob T, Schulz $H$, Behrendt $H_{\text {, }}$ Kreyling W: Total and regional deposition of ultrafine particles in a mouse model of allergic inflammation of the lung. Inhal Toxicol 2008, 20:585-593.

56. Asgharian B, Hofmann W, Bergmann R: Particle deposition in a multiplepath model of the human lung. Aerosol Sci Technol 2001, 34:332-339http:// www.thehamner.org/mppd/helpfiles/index.htm.

57. Lehnert BE, Morrow PE: Association of ${ }^{59}$ Iron oxide with alveolar macrophages during alveolar clearance. Exp Lung Res 1985, 9:1-16.

58. Sorokin SP, Brain JD: Pathways of clearance in mouse lungs exposed to iron oxide aerosols. Anat Rec 1975, 181:581-626.

59. Kreyling WG: Interspecies comparison of lung clearance of "insoluble" particles. J Aerosol Med 1990, 3:S93-S110.

60. Phalen RF, Oldham MJ: Tracheobronchial airway structure as revealed by casting techniques. Am Rev Respir Dis 1983, 128:S1-S4.

61. Lehnert BE, Ortiz JB, London JE, Valdez YE, Cline AF, Sebring RJ, Tietjen GL: Migratory behaviors of alveolar macrophages during the alveolar clearance of light to heavy burdens of particles. Exp Lung Res 1990, 16:451-479.

62. Geiser M, Gerber P, Maye I, Im Hof V, Gehr P: Retention of teflon particles in hamster lungs: A stereologic study. J Aerosol Med 2000, 13:43-55.

63. Geiser M, Leupin N, Maye I, Im Hof V, Gehr P: Interaction of fungal spores with the lungs: Distribution and retention of inhaled Calvatia excipuliformis spores. J Allergy Clin Immunol 2000, 106:92-100.

64. Kreyling WG, Ferron GA, Haider B: Metabolic fate of inhaled Co aerosols in beagle dogs. Health Phys 1986, 51:773-795.

65. Macklin CC: Pulmonary sumps, dust accumulations, alveolar fluid and lymph vessels. Acta Anat 1955, 23:1-33.

66. Adamson $\mathrm{IY}$, Bowden $\mathrm{DH}$ : Dose response of the pulmonary macrophagic system to various particulates and its relationship to transepithelial passage of free particles. Exp Lung Res 1981, 2:165-175.
67. Bowden DH, Adamson IY: Pathways of cellular efflux and particulate clearance after carbon instillation to the lung. J Pathol 1984, 143:117-125.

68. Peters A, Pope CA III: Cardiopulmonary mortality and air pollution. Lancet 2002, 360:1184-1185.

69. Oberdörster G, Oberdörster E, Oberdörster J: Nanotoxicology: an emerging discipline evolving from studies of ultrafine particles. Environ Health Perspect 2005, 113:823-839.

70. Kreyling WG, Möller W, Semmler-Behnke M, Oberdörster G: Particle dosimetry: deposition and clearance from the respiratory tract and translocation towards extra-pulmonary sites. Particle Toxicology Boca Raton: CRC Press, Taylor \& Francis CroupDonaldson K, Borm P 2007, 47-74.

71. Cedervall T, Lynch I, Lindman S, Berggard T, Thulin E, Nilsson H, Dawson KA, Linse S: Understanding the nanoparticle-protein corona using methods to quantify exchange rates and affinities of proteins for nanoparticles. Proc Natl Acad Sci USA 2007, 104:2050-2055.

72. Lynch I, Dawson KA: Protein-nanoparticle interactions. Nano Today 2008 3:40-47.

73. ESF 2005, ESF forward look on Nanomedicine. European Science Foundation Policy Briefings 2005http://www.esf.org/newsrelease/83/ SPB23Nanomedicine.pdf.

74. Kreuter J: Nanoparticulate systems for brain delivery of drugs. Adv Drug Deliv Rev 2001, 47:65-81.

75. Kreuter J: Influence of the surface properties on nanoparticle-mediated transport of drugs to the brain. J Nanosci Nanotech 2004, 4:484-488.

76. Kreuter J, Shamenkov D, Petrov V, Ramge P, Cychutek K, Koch-Brandt C, Alyautdin R: Apolipoprotein-mediated transport of nanoparticle-bound drugs across the blood-brain barrier. J Drug Target 2002, 10:317-325.

77. Kreyling WG, Tuch T, Peters A, Pitz M, Heinrich J, Stölzel M, Cyrys J, Heyder J, Wichmann HE: Diverging long-term trends in ambient urban particle mass and number concentrations associated with emission changes caused by the German unification. Atmos Environ 2003, 37:3841-3848.

78. Stone KC, Mercer RR, Gehr P, Stockstill B, Crapo JD: Allometric relationships of cell numbers and size in the mammalian lung. Am J Respir Cell Mol Biol 1992, 6:235-243.

79. Savi M, Kalberer M, Lang D, Ryser M, Fierz M, Gaschen A, Rička J, Geiser M: A novel exposure system for the efficient and controlled deposition of aerosol particles onto cell cultures. Environ Sci Techn 2008, 42:5667-5674.

80. Brown JS, Zeman KL, Bennett WD: Ultrafine particle deposition and clearance in the healthy and obstructed lung. Am J Respir Crit Care Med 2002, 166:1240-1247

81. Wiebert P, Sanchez-Crespo A, Falk R, Philipson K, Lundin A, Larsson S, Möller W, Kreyling WG, Svartengren M: No significant translocation of inhaled 35-nm carbon particles to the circulation in humans. Inhal Toxicol 2006, 18:741-747.

82. Wiebert P, Sanchez-Crespo A, Seitz J, Falk R, Philipson K, Kreyling WG, Möller W, Sommerer K, Larsson S, Svartengren M: Negligible clearance of ultrafine particles retained in healthy and affected human lungs. Eur Respir J 2006, 28:286-290.

83. Mills NL, Amin N, Robinson SD, Anand A, Davies J, Patel D, de la Fuente JM, Cassee FR, Boon NA, MacNee W, Millar AM, Donaldson K, Newby DE: Do inhaled carbon nanoparticles translocate directly into the circulation in humans?. Am J Respir Crit Care Med 2006, 173:426-431.

84. Mills NL, Tornqvist H, Robinson SD, Gonzalez M, Darnley K, MacNee W, Boon NA, Donaldson K, Blomberg A, Sandstrom T, Newby DE: Diesel exhaust inhalation causes vascular dysfunction and impaired endogenous fibrinolysis. Circulation 2005, 112:3930-3936.

85. Cruts B, van Etten L, Tornqvist H, Blomberg A, Sandstrom T, Mills NL, Borm PJA: Exposure to diesel exhaust induces changes in EEG in human volunteers. Part Fibre Toxicol 2008, 5:5

86. Auerbach O, Conston AS, Garfinkel L, Parks VR, Kaslow HD, Hammond EC Presence of asbestos bodies in organs other than the lung. Chest 1980, 77:133-137.

87. LeFevre ME, Green FH, Joel DD, Laqueur W: Frequency of black pigment in livers and spleens of coal workers: correlation with pulmonary pathology and occupational information. Hum Pathol 1982, 13:1121-1126.

88. Bianco A, Gibb FR, Kilpper RW, Landman S, Morrow PE: Studies of tantalum dust in the lungs. Radiology 1974, 112:549-556.

89. Miller FJ: Dosimetry of particles in laboratory animals and humans in relationship to issues surrounding lung overload and human health risk assessment: a critical review. Inhal Toxicol 2000, 12:19-57. 
90. Berry JP, Arnoux B, Stanislas G: A microanalytic study of particles transport across the alveoli: Role of blood platelets. Biomedicine 1977, 27:354-357.

91. Oberdörster G, Sharp Z, Atudorei V, Elder A, Gelein R, Lunts A, Kreyling WG, Cox C: Extrapulmonary translocation of ultrafine carbon particles following whole-body inhalation exposure of rats. J Toxicol Environ Health 2002, 65:1531-1543.

92. Takenaka S, Karg E, Roth C, Schulz H, Ziesenis A, Heinzmann U, Schramel P, Heyder J: Pulmonary and systemic distribution of inhaled ultrafine silver particles in rats. Environ Health Perspect 2001, 109(Suppl 4):547-551.

93. Takenaka S, Karg E, Kreyling WG, Lentner B, Moller W, Behnke-Semmler M, Jennen L, Walch A, Michalke B, Schramel P, Heyder J, Schulz H: Distribution pattern of inhaled ultrafine gold particles in the rat lung. Inhal Toxicol 2006, 18:733-740.

94. Semmler-Behnke M, Fertsch S, Schmid O, Wenk A, Kreyling WG: Uptake of $1.4 \mathrm{~mm}$ versus $18 \mathrm{~mm}$ gold particles by secondary target organs is size dependent in control and pregnants rats after intertracheal or intravenoiz application. Euro Nanoforum - Nanotechnology in Industrial Applications 2007, 102-104http://www.euronanoforum2007.de/download/ Proceedings\%20ENF2007.pdf.

95. Nemmar A, Hoylaerts MF, Hoet PH, Dinsdale D, Smith T, Xu H, Vermylen J, Nemery B: Ultrafine particles affect experimental thrombosis in an in vivo hamster model. Am J Respir Crit Care Med 2002, 166:998-1004.

96. Silva VM, Corson N, Elder A, Oberdörster G: The rat ear vein model for investigating in vivo thrombogenicity of ultrafine articles (UFP). Toxicol Sci 2005, 85:983-989

97. Khandoga A, Stampfl A, Takenaka S, Schulz H, Radykewicz R, Kreyling W, Krombach F: Ultrafine particles exert prothrombotic but not inflammatory effects on the hepatic microcirculation in healthy mice in vivo. Circulation 2004, 109:1320-1325

98. Kreyling WG, Semmler M, Möller W: Dosimetry and toxicology of ultrafine particles. J Aerosol Med 2004, 17:140-152.

99. Chen J, Tan M, Nemmar A, Song W, Dong M, Zhang G, Li Y: Quantification of extrapulmonary translocation of intratracheal-instilled particles in vivo in rats: Effect of lipopolysaccharide. Toxicology 2006, 222:195-201.

100. Semmler-Behnke M, Kreyling WG, Lipka J, Fertsch S, Wenk A, Takenaka S, Schmid G, Brandau W: Biodistribution of $1.4 \mathrm{~nm}$ and $18 \mathrm{~nm}$ gold particles in rats. Small 2008, 4:2108-2111.

101. Kuempel ED, Tran CL, Castranova V, Bailer AJ: Lung dosimetry and risk assessment of nanoparticles: evaluating and extending current models in rats and humans. Inhal Toxicol 2006, 18:717-724.

102. Kuempel ED, Tran CL, Smith RJ, Bailer AJ: A biomathematical model of particle clearance and retention in the lungs of coal miners. II. Evaluation of variability and uncertainty. Regulatory Toxicol Pharmacol 2001, 34:88-101.

103. Cullen RT, Tran CL, Buchanan D, Davis JM, Searl A, Jones AD, Donaldson K: Inhalation of poorly soluble particles. I. Differences in inflammatory response and clearance during exposure. Inhal Toxicol 2000, 12:1089-1111.

104. Tran CL, Buchanan D, Cullen RT, Searl A, Jones AD, Donaldson K: Inhalation of poorly soluble particles. II. Influence of particle surface area on inflammation and clearance. Inhal Toxicol 2000, 12:1113-1126.

105. Schäffler A, Menche N: Mensch Körper Krankheit Munich: Urban \& Fischer 1999, 300 .

\section{doi:10.1186/1743-8977-7-2}

Cite this article as: Geiser and Kreyling: Deposition and biokinetics of inhaled nanoparticles. Particle and Fibre Toxicology 2010 7:2.

\section{Submit your next manuscript to BioMed Central and take full advantage of:}

- Convenient online submission

- Thorough peer review

- No space constraints or color figure charges

- Immediate publication on acceptance

- Inclusion in PubMed, CAS, Scopus and Google Scholar

- Research which is freely available for redistribution

Submit your manuscript at www.biomedcentral.com/submit 